\title{
Hyperagency and the Good Life Does Extreme Enhancement threaten Meaning?
}

By John Danaher*

(forthcoming in Neuroethics DOI: 10.1007/s12152-013-9200-1)

\begin{abstract}
According to several authors, the enhancement project incorporates a quest for hyperagency - i.e. a state of affairs in which virtually every constitutive aspect of agency (beliefs, desires, moods, dispositions and so forth) is subject to our control and manipulation. This quest, it is claimed, undermines the conditions for a meaningful and worthwhile life. Thus, the enhancement project ought to be forestalled or rejected. How credible is this objection? In this article, I argue: "not very". I do so by evaluating four different versions of the "hyperagency" objection from four different authors. In each case I argue that the objection either fails outright or, at best, provides weak and defeasible grounds for avoiding enhancement. In addition to this, I argue that there are plausible grounds for thinking that enhancement helps, rather than hinders, us in living the good life.
\end{abstract}

Keywords: Enhancement; Hyperagency; Meaning of Life; Human Flourishing; Wellbeing;

* PhD (University College Cork, Ireland); Lecturer in Law, Keele University. 


\section{Introduction}

Could the pursuit of human enhancement undermine the good life? Several authors have argued that it could. Common to each is the claim that the enhancement project incorporates a quest for hyperagency -- i.e. a state of affairs in which virtually every constitutive aspect of agency (beliefs, desires, moods, dispositions and so forth) is subject to our control and manipulation -- and that this quest undermines one or more of the conditions for a flourishing, meaningful and worthwhile existence. This article addresses such objections — here termed "hyperagency objections" — in three parts.

Section 2, below, maps out the theoretical terrain within which the objections reside. It identifies their common features, and explains their underlying motivations. It suggests that they can be understood in light of the three most commonly-defended types of theory about the well-lived life: subjectivism, objectivism and hybridism.

Section 3 critically evaluates four hyperagency objections from four different authors. The first, from David Owens, argues that hyperagency removes all fixed points of reference from decision-making, disenchanting our view of the world and leaving us with a strange and "vertiginous" feeling. The second, from Saskia Nagel, argues that hyperagency leads to decision fatigue and choice overload, paralysing our decisionmaking processes and increasing our feelings of regret. The third, from Michael Hauskeller, argues that the pursuit of hyperagency undermines our appreciation for what is good about our lives right now, thereby leaving us with a constant feeling of dissatisfaction. And the fourth, which is inspired by Thomas Nagel, suggests that hyperagency heightens our appreciation for the absurdity of life. In each case, I argue that the objections either fail outright or provide, at best, weak and defeasible grounds for objecting to the enhancement project.

Section 4 then turns the table on these hyperagency objections by arguing that enhancement could actually improve our chances of living a worthwhile and meaningful life. The argument is made by considering two recent accounts of the well-lived life. The first, from Aaron Smuts, argues that the well-lived life consists in the causal production of objective goods. The second, from Thaddeus Metz, argues that the welllived life consists in transcending the animal self by contouring one's intellect to fundamental objects (at concept that will be defined below). In both instances, it is 
argued that enhancement, even in an extreme hyperagentic form, offers plausible mechanisms for satisfying the conditions needed for the good life.

\section{Hyperagency and Meaning}

The starting point for the analysis in this article is that there is an important and interesting connection between certain objections to enhancement and the debate about meaning and worthwhileness in life. Although this connection becomes clearer once I analyse the specific arguments in section 3, below, it is worth foregrounding that analysis with a general account. This can be accomplished by asking two questions: (i) what is a hyperagency objection to enhancement? and (ii) what are the most-common, general theories about the meaning and worthwhileness of life?

\section{1 - What is a hyperagency objection to enhancement?}

"Enhancement" is a notoriously vague and value-laden concept. For the purposes of this article, an "enhancement" will be defined as the deliberate application of technical and scientific knowledge to improve existing human capacities, move them beyond the range available to normal human beings, or add new capacities. ${ }^{1}$ According to this definition there is no assumption that an enhancement is necessarily good for an agent or for society. ${ }^{2}$

The "enhancement project" ${ }^{\prime 3}$ or "enterprise" is the name given to our collective and sometimes, but not always, coordinated efforts to enhance ourselves. This project has been ongoing for millennia, often taking different forms. Buchanan, for instance, has argued that literacy and farming are two classic examples of the enhancement project. More recently, I have argued that the growth of democratic, rights-based government is part of the enhancement project. ${ }^{5}$ Inclusion of such things within the scope of "enhancement" gives a sense of how broad and fuzzy the category can be.

\footnotetext{
${ }^{1}$ This follows, roughly, the definition offered by Buchanan (2011) p. 23.

${ }^{2}$ Contrary to Harris and Pacholcyzk (2013).

${ }^{3}$ Hauskeller, M. (2013) uses the term "project".

${ }^{4}$ Buchanan, A. (2011) uses the term "enterprise".

${ }^{5}$ Reference omitted for anonymity.
} 
Nevertheless, in contemporary debates, the focus is predominantly on a specific subset of enhancement technologies, namely biomedical enhancement technologies. These include things like drugs, brain stimulators, or methods of genetic engineering. The precise form does not matter too much here. What matters is that the targets of biomedical enhancement tend to be "internal" to the agent rather than "external". That is to say, unlike farming, literacy or democracy, biomedical enhancement directly targets the constitutive properties of individual human beings, e.g. their memories, their moods, their ability to concentrate, their muscle strength, their stamina and so on.

It is this direct targeting of the constitutive properties of human agency, combined with the degree of alteration envisaged, that gives rise to the hyperagency objection. The objection can be illustrated by way of a thought experiment from David Owens (whose argument will be evaluated more fully in section 3). ${ }^{6}$ The thought experiment asks us to imagine the "Pharmacy of the Future", in which drugs are available to manipulate every mood, belief or state of mind. Suppose you enter the pharmacy because you have an irrational belief that your romantic partner is cheating on you. The pharmacist has a drug that will solve your problem: Credon. This will strengthen your belief in your partner's fidelity, allowing you to continue the relationship without the mental anguish. Problem solved, right? Not necessarily. Before you decide to take Credon, the pharmacist, in an effort to give you all the relevant options, highlights another drug, Libermine, that could do the trick. The difference is that Libermine does not alter your belief in your partner's loyalty, it alters your attitude toward romantic fidelity. With Libermine the possibility of your partner's cheating won't cause any mental anguish. Maybe you should go for that? After all, your partner may someday cheat on you and it is probably better to treat this with equanimity than to have a groundless belief in their loyalty. At this stage, the decision problem becomes even more complex because there is a third drug that could solve your problem: Solox. This one changes your whole attitude toward romantic relationships, reducing your need for emotional dependence and encouraging you to have a string of casual relationships in lieu of a more "serious" long-term one. This could be the best option of all: less dependence on other people, who have a tendency to disappoint you anyway.

This particular scenario may or may not be plausible. That's not important here. What is important is that the biomedical wave of the enhancement project pushes us

\footnotetext{
${ }^{6}$ Owens (2007)
} 
toward developing these kinds of abilities, and this prompts a negative reaction, at least from certain people. As Owens himself puts it: ${ }^{7}$

"The pharmacist is giving you too much choice, more choice than you can think of any grounds for making. By insisting that you take nothing as given, that you regard every aspect of your character as mutable, as subject to your will, the pharmacist puts you in an irresolvable quandary. You can't handle such total control."

This captures the essence of the hyperagency objection. The claim is that control over this many constitutive aspects of your agency is not welcome. So to the extent that the enhancement project gives us that control - or indeed to the extent that it causes us to desire that $\operatorname{control}^{8}$ - it is a bad thing. This allows us to characterise as a hyperagency objection any argument that fits the following argument template:

\section{Hyperagency Objection Template}

(1) The enhancement project will cause us to believe in, pursue or attain a state of hyperagency.

(2) If we believe in, pursue, or attain a state of hyperagency, negative consequences $X_{1} \ldots X_{n}$ follows.

(3) Any activity that leads to negative consequences $X_{1} \ldots X_{n}$ should be forestalled or rethought.

(4) Therefore, the enhancement project should be forestalled or rethought.

As it happens, there is a good deal of variation among hyperagency objections in terms of how they specify the key variables in premise (2). In what follows, I address versions of the objection that focus on the negative consequences for personal fulfillment and meaning in life, but there are also variants that focus on the negative consequences for social justice. They will not be addressed in this article. ${ }^{9}$ Furthermore, there are

\footnotetext{
${ }^{7}$ Owens (2011), p. 176

${ }^{8}$ As we'll see below, both Michael Hauskeller's version of the objection can be run merely from the desire or pursuit of hyperagency.

${ }^{9}$ I have a separate, forthcoming article that deals with this set of objections.
} 
objections to enhancement that are connected to hyperagency objections, but in an indirect fashion. These are the objections that focus on the alleged inauthenticity of enhancement-assisted personal achievement. Such objections focus less on the effects of enhancement on autonomy and control (as do hyperagency objections), and more on the effects of enhancement on one's personal life history or narrative. For the most part, I will avoid dealing with these concerns, but as we shall see below, defending the enhancement project from proponents of the hyperagency objection will lead us to touch upon these other objections too.

Before moving on to consider the next question — how does all this intersect with the debate about the good life? - it is worth briefly commenting on why it's worth treating hyperagency objections as a family. To me, the main benefits come from the fact that they direct our attention to a common underlying set of (allegedly) wrong or bad-making mechanisms brought about by enhancement. Probing and testing those mechanisms seems like a useful thing to do.

\section{2 - What are the general theories of meaning and worthwhileness in life?}

If the enhancement debate involves some terminological subtleties, the debate about the meaning and worthwhileness of life is no better. So many different terms are thrown about, oftentimes interchangeably, that it is sometimes difficult to find your bearings. People talk about the "meaningful" life, the "significant" life, the "worthwhile" life, the "fulfilling" or "flourishing" life, or just the "good" life, without always marking the differences between these concepts.

I will try to avoid this terminological muddle as much as possible. For my purposes, the meaningful life is defined as the one that satisfies some minimal set of necessary and sufficient conditions of value; and the worthwhile life is defined as the one that crosses some higher threshold of meaningfulness. ${ }^{10}$ Thus, both concepts implicate and appeal to the same set of underlying conditions of value. They simply represent different points along a spectrum for the satisfaction of those conditions.

Broadly speaking, there are three accounts of what it takes to live a meaningful and worthwhile life. They are:

\footnotetext{
${ }^{10}$ Smuts, forthcoming; and Metz (2002)
} 
Subjectivism: which holds that the underlying conditions of value are subjective in nature. In other words, that in order to live a meaningful or worthwhile life, an agent has to achieve a certain kind of subjective state (e.g. conscious pleasure or desire-satisfaction etc.)

Objectivism: which holds that the underlying conditions of value are objective in nature. In other words, that in order to live a meaningful or worthwhile life, an agent has to bring about or participate in a certain kind of objective state (e.g. curing sickness or pleasing God)

Hybridism: which holds that the underlying conditions of value are partly subjective and partly objective. In other words, that in order to live a meaningful or worthwhile life, an agent has to achieve a certain kind of subjective state and bring about or participate in a certain kind of objective state. The most famous contemporary theory of this kind is probably Susan Wolf's "fitting fulfillment" theory, ${ }^{11}$ which holds, roughly, that the meaningful life is one in which an agent is subjectively fulfilled by objectively valuable projects or ends.

The initial claim I want to make is that hyperagency objections to enhancement can be interpreted in light of these three categories of theory. In other words, they can all be viewed as arguments claiming that one or more of the conditions needed for a meaningful or worthwhile life are undermined by hyperagency. Most commonly, they will appeal to subjectivist or hybridist theories of meaning. This is because, in their specification of the key variables in the hyperagency objection template, they speak to the potential for enhancement to lead to an undesirable, intolerable, unpleasant or insupportable state of agency. This much is clear from Owens's thought experiment, which asks us to consider the impact of hyperagency on our own internal decisionmaking processes. The experiment is supposed to induce a disorienting and disquieting subjective effect. That said, hyperagency objections can also be interpreted as belonging to some objectivist theories of meaning, at least to the extent that those theories appeal to the properties of agency (either as being constitutive or causally-related to the conditions of meaning).

\footnotetext{
${ }^{11}$ Wolf (2012)
} 


\section{Four Hyperagency Objections}

This section analyses and evaluates four separate versions of the hyperagency objection. Each appeals to a slightly different characterisation of the conditions necessary for a meaningful and worthwhile life. In each case, I argue that the objection either fails outright, or provides at best weak and defeasible grounds for impeding the enhancement project.

\section{1 - Owens's and the Fixed Point Objection}

We start by considering Owens's objection. This objection appeals, ${ }^{12}$ in the first instance, to a classic subjectivist theory of meaning, oftentimes attributed to Richard Taylor. ${ }^{13}$ This theory holds that life is meaningful and worthwhile in proportion to the number of desires an agent can satisfy. Strictly interpreted this theory can have some absurd implications, ${ }^{14}$ as we shall see in moment, but we'll work with it for the time being, refining our understanding of Owens's objection as we go along.

In the initial phases of his critique, Owens points out that the world presents obstacles to desire-fulfillment. These obstacles take a variety of forms. Three can be mentioned here: external obstacles (which have to do with the structure of the external world), doxastic obstacles (which arise from false beliefs) and affective obstacles (which arise from our own subjective desires, moods and emotions). To illustrate: I cannot go on my desired trip to Mars, because there are external obstacles preventing such a trip at this moment in time; I cannot cross the graveyard on my way home at night because of my superstitious beliefs; and I cannot fly to Australia because of my affective fear of flying.

Science is good at removing these obstacles to desire-fulfillment. Scientific knowledge can provide us with more accurate, less superstitious beliefs; and scientific technologies can eliminate both external and internal obstacles to desire-fulfillment.

\footnotetext{
12 Owens (2007) disclaims any view about whether there is, in fact, meaning in life, or whether meaning in life is entirely subjective, but he does invoke the desire-fulfillment standard throughout his article, so I think my interpretation here is fair.

${ }^{13}$ See Taylor, R. (2008 - reprint). Taylor later abandoned this view, but see Bruckner, D. (unpublished) for an updated defence.

${ }^{14}$ See Wielenberg, E. (2005) and the grinning excrement eater objection. Also, Smuts, forthcoming.
} 
Thus, for example, the creation of inter-planetary spacecraft could help me to fulfil my Mars-desire; the scientific debunking of ghost stories can cure me of my superstitious beliefs; and the availability of anti-anxiety drugs might help me get to Australia. Since enhancement technologies could have similar and arguably more pervasive mood and belief-altering effects, one could argue that they are a good thing: they remove more and more obstacles to desire fulfillment by giving us more and more control over our internal makeup.

Owens doesn't quite see it this way. In the Pharmacy of the Future, we are provided with innumerable obstacle-removing drugs, but the prospect is not a welcome one. The problem is that the pharmacist is offering us "too much choice...[we] cannot handle such total control". ${ }^{15}$ The enhancement enterprise encourages us to see our internal states - desires, beliefs, emotions, and moods - as contingent, when we need them to be fixed. ${ }^{16}$ As he puts it, "a successful science of mind...threatens to remove the fixed points that are needed to make decision making possible at all." ${ }^{\prime 17}$ This will lead to a "vertiginous" feeling because science suggests that "there is nothing normative about man's actual needs or his actual desires". 18

There seem to be two distinct worries pervading Owens's comments. The first, more mundane and subjectivist worry, is that by attaining a state of hyperagency we are stranded in a sea of decisional confusion, flapping about with "too much control". This thwarts our ability to satisfy desires, because we are unsure of what we really want. The second, more metaphysical worry, is that by attaining a state of hyperagency we remove the fixed normative points that are needed for decision-making. This is a more fundamental critique of hyperagency, suggesting that once a certain threshold of control is crossed, the value-based decision-making necessary for satisfying the conditions of meaning will be undermined.

In summary, Owens is fleshing out the key premise of the hyperagency objection in the following manner:

\footnotetext{
${ }^{15}$ Owens (2011), p. 176

${ }^{16}$ Owens (2007), p. 173-174

${ }^{17}$ Owens (2007), p. 177.

${ }^{18}$ Owens (2007), p. 177
} 
(2*) If we attain a state of hyperagency, we will (a) be stranded in a sea of decisional confusion; or (b) remove the fixed normative points we need for decision-making.

Three responses to this version of the objection can be offered here.

First, note how this argument works from an "attainment" version of the motivating premise. In other words, the negative consequences do not follow until we have crossed the threshold of control and attained the state of hyperagency. It is quite difficult to say when that threshold has been crossed, but even if we assume it is crossed in cases like that of the Pharmacy of the Future, it is not clear that there is anything to worry about here and now. Certainly, the kinds of enhancement technology we have available to us at this moment in time do not grant us easy, reliable and comprehensive control over our internal states. We are a long way from that, and for all we know we may run into hard limits of manipulability before the threshold is ever crossed.

Still, this is a somewhat hollow critique, relying on speculations about the future state of technology. A more telling critique, targeted specifically at the decisional confusion claim is this: there is no reason to think that crossing such a threshold would confuse us in any event. In this regard, Owens's analysis of his own thought experiment is psychologically implausible. In the Pharmacy of the Future, the seeds of confusion are sown when the pharmacist presents the patient with more and more choices about how to resolve their romantic difficulties. But if one entered the pharmacy with the desire to maintain one's relationship, the mere fact that there were other drugs that could resolve the problem in a different way wouldn't necessarily lead to confusion. The primary motivating desire would allow you to automatically filter out or ignore certain options, thereby limiting the scope for decisional confusion. You have a primary desire to stay with your partner and to trust them, so Credon is going to seem like an obvious choice; Libermine might be considered; but Solox would certainly just be filtered out.

A different example might make this response more compelling. If someone told me that there was a drug that would give me a tremendous desire for chocolate milk (or any other substance), this wouldn't suddenly lead to decisional confusion. I currently have no desire for chocolate milk, and the mere availability of a drug that would induce 
that desire doesn't make it any more attractive. To create confusion, the available choices would have to work with some conflicting set of underlying desires, but those won't always (or even very often) be present. Many potential manipulations of our character will simply seem undesirable or uninteresting and so we won't be confused by them. Admittedly, this response turns on an empirical claim about how people will react to new choices. I think my analysis is plausible, but it is theoretical not empirical. There may be evidence suggesting that Owens's fear is empirically well-founded. We'll deal with this possibility below when looking at Saskia Nagel's argument.

This brings us to a third response, this one targeting the fixed points claim. Owens's argument on this score seems particularly problematic. The notion that decision-making would become unconstrained by normative standards once we obtain a state of hyperagency ${ }^{19}$ assumes not just a subjectivist account of meaning, but an extreme subjectivist and relativist account of value. It seems to be saying: Only if $\mathrm{X}$ is desired, will X be valuable. But this is absurd. As others have argued, ${ }^{20}$ this implies that we must treat an innate desire to murder, rape or kill as being normative for the agent; and believe that those who fulfil such desires live meaningful and worthwhile lives. Surely this cannot be? If at least some ethical and moral standards are non-relative and objective (in the sense that they are not simply whatever we decide them to be) then they will continue to provide normative constraints even after a state of hyperagency is obtained.

In short, Owens's hyperagency objection is flawed. He provides no good reason for thinking that the enhancement project will in fact lead to decision-paralysis, and his "fixed points"-objection presupposes an extreme and implausible account of subjective value.

\section{2 - Saskia Nagel and The Burden of Choice}

For all its shortcomings, Owens's critique may have kernel of good sense. But if so it is perhaps better expressed by Saskia Nagel. In her article, "Too Much of a Good Thing? Enhancement and the Burden of Self-Determination", Nagel argues that

\footnotetext{
${ }^{19}$ It should be noted that C.S. Lewis made a very similar claim in his essay The Abolition of Man. See Lewis (2008)

${ }^{20}$ Wielenberg (2005) and Smuts (forthcoming)
} 
enhancement could have a negative impact on well-being by opening up a greater space of possible options to an agent. As she puts it herself:

"The thesis of the present paper is that the growing space of options to choose from which is opened by the potential of neuroenhancement needs to be carefully scrutinized: Studies from psychology and consumer research teach us that the increase in possibilities might turn out not to be for our best and in fact hinder human flourishing., 21

In defence of this thesis, Nagel presents three reasons for thinking that hyperagency could undermine human flourishing. These reasons focus primarily on subjective conditions of well-being and so belong mainly within the subjectivist and hybridist schools of thought. Still, the kinds of problems to which she alludes (e.g. decision paralysis) could also block access to objective conditions of meaning.

Her first reason appeals to work done by Barry Schwartz (and colleagues) on the so-called paradox of choice. ${ }^{22}$ A common liberal-economic belief is that individuals are the best judges of their own well-being and hence it is better (within moral/ethical constraints) to leave them to make their own decisions about what to do with their lives. The best we can do, from a policy perspective, is to supply them with more and more choices. Doing so will allow them to coordinate on the profile of options that best suits their idiosyncrasies. Hence, one of the prevalent features of the capitalist marketplace is the provision of a bewildering array of consumer goods, often with minimal variation between them. Schwartz's research suggests that far from being conducive to wellbeing, this increased number of choices can actually be a hindrance. With so many options to compute, people can get stuck in decision problems. This reduces their subjective well-being both by inducing confusion and by preventing them from making beneficial decisions. Nagel co-opts this argument to the enhancement debate: enhancement means more options, which means choice overload, which means less flourishing. The affinities with Owens should be clear. Indeed, Nagel appeals to an almost identical thought experiment when making her case. ${ }^{23}$

\footnotetext{
${ }^{21}$ Nagel (2010)

${ }^{22}$ Summarised in Schwartz (2004)

${ }^{23}$ Nagel (2010) p. 112.
} 
Nagel's second and third reasons for challenging hyperagency play upon the same theme. Pointing once more to the increased number of options that might become available, she highlights two negative implications. The first is that by increasing the number of options available to any one agent we also increase the opportunities for regret, and since regret impacts negatively on subjective well-being, our subjective well-being is reduced. The second implication is that an increased number of options leads to an increased perception of responsibility for one's failings: if I could have avoided some mishap by taking (say) a cognitive enhancing drug, then I may feel accountable or blameworthy for not doing so. This leads to feelings of guilt and associated mental anguish. This could be exacerbated by reinforcement from social perceptions of responsibility. Although these two reasons for objecting to hyperagency play off one another, they are distinct: feelings of regret and feelings of guilt or blameworthiness are different. The latter are always linked to moral standards of conduct, whereas the former are not.

To put this more succinctly, Nagel fleshes out the key premise of the hyperagency objection in the following manner:

$(2 * *)$ If we believe in or attain a state of hyperagency, we will (a) be stranded in a sea of decisional confusion; (b) experience increased feelings of regret; and/or (c) experience increased feelings of guilt/responsibility.

Before I respond to this argument, a quick note about the "believe in or attain"equivocation in its antecedent clause. Generally speaking, the negative consequences to which the argument points only arise if the number of options available to the agent really does cross the relevant threshold, i.e. if the agent "attains" a state of hyperagency. Still, how the agent subjectively perceives the decision-making situation is part of the picture. My only comment on this is that it should be easy to correct any misperception the agent has about the decision-making situation. Thus, if they think they are in a state of hyperagency, but in reality they are not, the negative consequences need not follow because their misperception can be corrected. This makes it quite unlike Hauskeller's version of the argument, which will be discussed below. Hauskeller's argument works entirely from subjective perceptions. With that observation out of the way, I offer replies to each of Nagel's three claims. 
Turning first to the claim about decision paralysis, this obviously replicates Owens's critique. The difference is that Nagel recruits some psychological evidence in support of her claim. How persuasive is this evidence? The choice overload hypothesis associated with Schwartz's work is not without its problems. In a meta-analysis published in 2010, Scheibehenne et $\mathrm{al}^{24}$ found that there was a negligible effect size for choice overload across 50 studies, suggesting that the evidence for the claim is something of a mixed bag. This might be enough to diffuse Nagel's criticism, but as the authors of that study point out: "the variance between the effect sizes in the whole data set is higher than what would be expected by a mere random distribution around an effect size of zero". ${ }^{25}$ In other words, they think there might be something going on here. Increasing the number of options available to the agent won't by itself reliably produce the effect, but when combined with other factors it could. The question is what might those other factors be?

Scheibehenne et al list two major factors that have been found to modulate the effect. ${ }^{26}$ First, there is the way in which the decision problem is structured. It has been found that organising the options into categories lessens the effect; that the number of difficult trade-offs involved in the decision exacerbates the effect; that the increased time pressures in experimental settings may trigger the problem; and that information overload may be the primary trigger, not choice overload. ${ }^{27}$ Second, there are the strategies and characteristics that the decision-maker brings to bear on the decision problem. It has been found that if people decide that they want something from a given choice set before making a choice within that set, the effect is lessened; that those with a satisficing mindset suffer less than those with a maximising mindset; ${ }^{28}$ that those who are asked to justify their decision after the fact suffer more than those who are not; and that many people can overcome the problem by adopting simple decision heuristics. This last observation is particularly interesting as it suggests that, in practice, people can adapt to the increased number of options. ${ }^{29}$

\footnotetext{
${ }^{24}$ Scheibehenne, B., Greifeneder, R. and Todd, P.M. (2010).

${ }^{25}$ Scheibehenne, B., Greifeneder, R. and Todd, P.M. (2010), at 418.

${ }^{26}$ References for the modulating factors discussed in this paragraph can be found in Scheibehenne et al (2010), pp. 419-421.

${ }^{27}$ Information can be measured formally as the entropy of a choice set, which can be increased in ways other than by adding more choices.

${ }^{28}$ A maximiser is someone who looks to maximise expected utility in any given choice set; a satisficer is someone who looks to cross an acceptability threshold in any given choice set. The term "satisficing" was introduced by Herbert Simon.

${ }^{29}$ Additionally, Scheibehenne et al (2010) note that perceptions of quality can have an impact: if the choice set is deemed to be of low overall quality, an increased number of options is welcome, but not
} 
What impact does this have on Nagel's argument? It is certainly not my place to adjudicate on the empirical evidence, or to question whether the phenomenon of choice overload is real or not. Nevertheless, I do think that the fact that the phenomenon is not robust, and that it can be modulated by a number of factors, weakens considerably Nagel's first concern about hyperagency. First of all, the non-robustness suggests that this may not be a significant impediment to enhancement, i.e. when it comes to assessing the overall costs and benefits of enhancement, choice overload should not be assigned too much weight. Second, the modulating factors could be exploited by proponents of the enhancement project to avoid or minimise any predicted problems. Thus, in the Pharmacy of the Future (say) the options could be categorised, the time pressures could be lessened and agents could be encouraged to adopt simple decision heuristics to filter out some of the options quickly. Indeed, as I suggested above, this is very probably what will happen anyway: agents who come in with one particular problem are likely to ignore options that do not directly address that problem (even if those options circumvent or lessen the problem in an indirect manner).

This brings us to the second aspect of Nagel's objection, the one about increased feelings of regret. Her argument has some prima facie plausibility. More options certainly means more opportunities for regret. And as Nagel herself notes, ${ }^{30}$ there is some evidence to suggest that regretting the things not done is worse than regretting things done (though only in the long term - in the short term people regret what they have done more than what they have not). Still, I would note three things. First, regret is not always a bad thing: negative experiences can be an important part of a person's life narrative, and they can provide powerful motivation to make better decisions in the future. Second, research suggests that it is not so much the number of options that increases feelings of regret as it is the magnitude and irreversibility of the opportunity associated with each option. ${ }^{31}$ In other words, you regret the big decisions that you cannot go back on, more than the little decisions that you can go back on. Arguably, the availability of enhancement technologies could ameliorate this problem: if we can increase life expectancy, and increase the ease with which people can change their moods and dispositions, then there could be fewer serious lost opportunities. Third, and

when it is of high quality. They also note that studies on the phenomenon may be ignoring the pleasure people experience by experimenting with something, even if they don't ultimately like it.

${ }^{30}$ Nagel (2010), p. 113

${ }^{31}$ Roese, N. J. and Somerville, A. (2005); and Beike, DR, Markman, KD and Karadogan, F. (2009) 
following on from this, there would seem to be obvious ways in which the enhancement project could be channeled so as to minimise regret. Research and development of memory-dampening drugs is the most obvious example of this. If people can therapeutically forget certain aspects of their lives - maybe not by removing the declarative memories of past decisions but rather by dampening their emotional salience — then regret could be minimised, if not eliminated. Complete elimination may not be welcome, of course, but my only point here is that Nagel's regret worry should not dissuade us from developing enhancement technologies since those technologies could actually address that worry.

That leaves us with Nagel's third concern, the one about increased feelings of responsibility. I will say relatively little about this here since I address it at length elsewhere. ${ }^{32}$ Suffice to say, I think it is a credible worry. ${ }^{33}$ For example, it seems plausible to me that the failure of a pilot to take a cognitively enhancing drug, when that drug would have reduced the risk of pilot error, could be liability-engendering. In this manner, an increased compliance burden could be placed on certain people whenever enhancement technologies reduce the risk associated with their activities. This could have negative implications for well-being insofar as an increased compliance burden is arduous, reduces opportunities, and limits freedom. Nevertheless, two countervailing considerations need to be borne in mind. The first is that the imposition of responsibility should always be guided by sound moral reasoning: if an agent deserves to be held responsible, then there might be nothing intrinsically wrong with imposing an increased compliance burden on them. The second observation is that if we think there is something objectionable about imposing an increased compliance burden on someone, we can be creative about the way in which we distribute the burdens. It is not always the case that the increased compliance burden tracks the individual who is best placed to avoid the risks. For instance, the thin skull rule of liability in tort and criminal law shifts a compliance burden away from the person with the "thin skull" - who is arguably the one best placed to avoid the risks associated with their own thin skull — and onto the surrounding society. Something similar could occur in the case of the pilot: instead of placing the entire compliance burden on her, some of it could be distributed onto other institutional actors (e.g. they may be required to remind the pilot, supply her with the

\footnotetext{
32 Omitted

${ }^{33}$ Vincent (2013) argues for the thesis at great length. It also provides the impetus for the ongoing

“Enhancing Responsibility” project. See http://enhancingresponsibility.com/ (visited 1/12/13)
} 
requisite drugs, and so forth). In this manner, the negative impacts on well-being could be minimised.

To summarise, Nagel does raise three interesting worries about the impact of hyperagency on meaning and worthwhileness, but they are not significant enough to forestall or delay the enhancement project. The worries are either not robust enough to truly worry about, or else are easily avoided through the careful planning and development of enhancement technologies.

One general point worth raising here, which is relevant not just to my responses to Owen and Nagel but also to the arguments considered below, is whether in defending enhancement from hyperagency objections I am being insufficiently attentive to the overall social benefits of the enhancement project. Consider how, in my response to both Owens and Nagel, I suggest that there are ways in which the deleterious consequences to which they point could be avoided by most people. But what if some people are still susceptible to these negative consequences? Could it be that the depletions in meaning and worthwhileness suffered by those few is sufficient to warrant forestalling the enhancement project as a whole? Perhaps on the grounds that reductions in meaning have some sort of priority over productions of meaning? ${ }^{34}$

I would argue that this depends largely on the background ethical/normative framework one brings to bear on the enhancement project. If you adopt some form of negative consequentialism (i.e. minimise the bad) then this argument will hold some water. But if you adopt a more traditional positive form of consequentialism, it would not, particularly in light of the fact that, as I shall argue later on, enhancement can actually increase meaning. Similarly, and more in keeping with my actual views, ${ }^{35}$ if one approaches the enhancement project from a broadly liberal-political perspective, this critique seems misguided. Even if it were true that some people suffered negative consequences, that would provide no justification for denying them the opportunity to make use of enhancement, nor indeed for denying that opportunity to others who may benefit from enhancement. To be clear, I am not suggesting that the relevant political authorities have an obligation to provide enhancement to people - though they might as is hinted at by the responsibility example - I am simply saying they would not have the

\footnotetext{
${ }^{34} \mathrm{I}$ am indebted to an anonymous reviewer for bringing this objection to my attention.

${ }^{35}$ Reference omitted.
} 
legitimate authority to deny people access to that technology, especially when the potential harm that will be suffered is an individual, private matter.

\section{3 - Hauskeller and the Relativisation of Value}

A third argument against hyperagency can be found in the work of Michael Hauskeller. ${ }^{36}$ His argument can be interpreted as working within a fitting fulfillment theory of meaning, as it is concerned about the way in which subjective states of mind join-up with objective goods. Unlike the preceding arguments, Hauskeller's objection works from concerns about the mere pursuit of hyperagency, not from its actual attainment. As such, his argument is trickier for the proponent of enhancement to deal with.

The argument itself is a refinement and reconstruction of Michael Sandel's famous giftedness argument. Sandel's concern was that the drive towards hyperagency would cause us to lose any appreciation for the gifted aspects of our lives. In this context, a gifted aspect of our lives is one that is more-or-less fixed (i.e. not easily alterable or manipulable) and of benefit to us. ${ }^{37} \mathrm{~A}$ desire to control and manipulate every aspect of our lives, including the constitutive aspects of our agency, would clearly limit the space of giftedness. So this aspect of the argument has some merit. It is rather more difficult, however, to say why limiting the space of giftedness is a problem.

Hauskeller gamely tries to identify some of the problems in his article, one of which is relevant here. ${ }^{38}$ As he sees it, one of the chief issues with the drive towards hyperagency is that it makes the better the enemy of the good. Those who are enamoured with enhancement, and who want to improve themselves, tend to have a relativistic understanding of value. That is to say, the possibility that things could be so much better in the future reduces their appreciation for what is good in the here and now. This is because what they have now seems "worse" than what they could have in

\footnotetext{
${ }^{36}$ The argument can be found in Hauskeller (2011) and (2013), chapter 10.

${ }^{37}$ The goodness or benefit of the gifted is a key part of Hauskeller's argument. See Hauskeller (2011), p. $62 \mathrm{ff}$.

${ }^{38}$ The other concerns the impact on social solidarity, which I will deal with in a separate paper on this topic. Omitted.
} 
the future. Hauskeller singles out the techno-optimism of Nick Bostrom for particular scrutiny in this regard. In one of his articles, ${ }^{39}$ Bostrom quotes from Bishop Berkeley:

"I am apt to think, if we knew what it was to be an angel for one hour, we should return to this world, though it were to sit on the brightest throne in it, with vastly more loathing and reluctance than we would now descend into a loathsome dungeon or sepulchre."

Bostrom then proceeds to enumerate the wonders that await us in our posthuman future, when we have radically enhanced our capacities. Everyday will be "joy" we are told; we will develop new art forms that exploit our advanced capacities and sensibilities, and listen to "music that is to Mozart what Mozart is to bad Muzak". 40

Bostrom may find this enticing, but Hauskeller does not. By relativising the value of great art in this manner, we risk dulling our appreciation for what we have: "everything that excites, fascinates and enraptures us today will no longer have any interest to us whatsoever." ${ }^{41}$ What's more, this will hold true even if we do enhance our capacities in the radical manner envisaged by Bostrom. Why? Because there will always be the hope of an even better world just over the technological horizon. In this sense, Hauskeller's concern about the drive for hyperagency can clearly be interpreted in terms of the subjective conditions for meaning. He is worried that our quest to improve ourselves will lead to a persistent, listless dissatisfaction with the lives we have. In other words, he fleshes out the key premise of the hyperagency objection in the following manner:

$\left(2^{* * *}\right)$ If we pursue a state of hyperagency, we risk losing any appreciation for the intrinsic goods we now have (because pursuing hyperagency always promises us "better" goods).

I think we can agree with Hauskeller that listless dissatisfaction of this sort would undermine the good life. The question is whether this is likely. Because Hauskeller works from the mere pursuit of hyperagency it is, as I said previously, more difficult to deal with his argument. By appealing to perceptions and misperceptions about possible

\footnotetext{
${ }^{39}$ Bostrom (2008)

${ }^{40}$ Bostrom (2008), p. 112

${ }^{41}$ Hauskeller (2013), p. 177
} 
futures, the argument avoids some of the easy critiques mounted above. Still, there are some things to be said against it.

First, note that the drive for hyperagency cannot deny the intrinsic value of everything. In particular, it cannot deny the intrinsic value of self-improvement since that value is at the core of the enhancement project. Of course, one may deny the intrinsic value of self-improvement on other grounds, but I think that's an implausible denial. I certainly derive a great deal of intrinsic satisfaction from improving my capacities and abilities, irrespective of where this ultimately leads me. I see no reason why this intrinsic value could not be sustained with the pursuit of hyperagency. I admit, however, that this response is somewhat weak since it doesn't restore the other values Hauskeller feared losing.

This leads me to a second, more important, reply. It seems to me that Hauskeller's argument is guilty of an implausible overstatement. Even if we grant that it is dangerous to make the better the enemy of the good, is it really likely that everyone will start doing this? Maybe techno-utopians like Bostrom would succumb to this listless dissatisfaction, but what about the rest of us? The pursuit of enhanced agency is not necessarily guided or wedded to techno-utopianism. As Frances Kamm points out, ${ }^{42}$ one could pursue incremental improvements without being motivated by a drive for hyperagency. In other words, you could gradually pursue advances across a range of agency capacities, for reasons that are not connected directly to self-improvement, and then perhaps stumble into a state of hyperagency, but at no point in the transition would you be driven by the desire for some idealised posthuman world.

To be fair to him, Hauskeller identifies and responds to Kamm's critique. He says: ${ }^{43}$

"[For my argument to work] the actual motives people have for promoting and seeking human enhancement are largely irrelevant. I need not be motivated by a drive to mastery in order to fall victim to it. A particular kind of action can be an expression of the drive to mastery without being motivated by it...[I am] not

\footnotetext{
${ }^{42}$ Kamm (2009)

${ }^{43}$ Hauskeller (2013), p. 180. I have doctored the original text somewhat. Kamm's argument was originally made in response to Sandel, and so Hauskeller refers to Sandel's claims in his discussion. But since Hauskeller is trying to defend Sandel's argument, I take it that attributing those arguments to him is not an unfair distortion of his response to Kamm.
} 
concerned with a particular vice that befalls individuals, but rather a 'habit of mind and way of being' that pervades the beliefs and practices of a community, society of culture."

This reply seems to border on self-contradiction. Hauskeller is trying to claim that the motives and attitudes of individuals are irrelevant to his argument; that the real concern is with a particular "habit of mind" that pervades our communities. But this is an impossibly fine line to walk. His entire argument was built upon the claim that those pursuing hyperagency would be inclined towards a listless dissatisfaction with what they had, and a careless relativisation of value. That argument can only work if such dissatisfaction is experienced by actual individuals and if such relativisation is consciously represented in their brains. To claim otherwise is to undermine that argument.

In the end, then, we are left with two arguments: Hauskeller's, which makes a somewhat plausible case for the view that the pursuit of hyperagency will lead to less subjective well-being (for at least some people); and mine, which makes a somewhat plausible case for thinking this need not be so (I should add that my argument leaves open the possibility that the self-improvements attained through enhancement will increase subjective well-being). I don't think we can say definitively which one is right, since we are both guilty of armchair psychologising, but that in itself would seem to diffuse the objection.

This conclusion touches upon a more general issue that is worth raising at this juncture. ${ }^{44}$ Most of the hyperagency objections considered here depend on extreme and extremely speculative accounts of what may happen if hyperagentic enhancement becomes a reality. My response to each of these objections is to suggest that at best they provide weak and defeasible grounds for rejecting enhancement. But one could argue that given the high level of uncertainty and speculation that pervades this debate, my response is itself weak and defeasible: things may not work out as I envisage. What I want to suggest by way of reply is that my defence of the enhancement project is more robust than it first appears. Below, I'll argue that there are plausible grounds for thinking that enhancement, even in an extreme hyperagentic form, can increase our chances of living a meaningful and worthwhile life. These grounds are based on

\footnotetext{
${ }^{44} \mathrm{I}$ am indebted to an anonymous reviewer for pressing me on this point.
} 
plausible accounts of what we currently deem valuable. When coupled with the weak and defeasible nature of the hyperagency objections, they can support the view that the enhancement project is a good bet, not something that is guaranteed to make us live more fulfilling lives, but something that is more likely than not to get us there.

\section{4 - Thomas Nagel and a Heightened Appreciation for the Absurd}

A final meaning-based objection to hyperagency can be found in Thomas Nagel's famous argument for the absurdity of life. ${ }^{45}$ To be clear, the application of this argument to the enhancement debate is something I am proposing, not something that Nagel himself has ever suggested. Nevertheless, I think the argument is worth considering, both in the interests of completeness, and insofar as it connects with the concerns found in the preceding arguments. To see how it might work, we need to review Nagel's argument first, and then consider it in light of the impact of enhancement.

Nagel's argument is pretty straightforward. It works from a simple principle of absurdity, which I shall here call Nagel's Absurdity Principle (NAP): ${ }^{46}$

NAP: Our lives are absurd if there is a persistent and inescapable discrepancy between what we hope and aspire to and what we can actually achieve.

The claim then mounted by Nagel is that there is, in fact, a persistent and inescapable discrepancy of this sort; one that pervades our lives and cannot be avoided. This is the discrepancy between our desire for our lives to be treated as matters of serious concern, and the unavoidability of philosophical doubt. He defends the existence of the first of these desires with the following observation: ${ }^{47}$

"[People] spend enormous quantities of energy, risk and calculation on the details [of their lives]. Think of how an ordinary individual sweats over his appearance, his health, his sex life, his emotional honesty, his social utility, his self-knowledge, the quality of his ties with family, colleagues, and friends, how well he does his job, whether he understands the world and what is going on in it.

\footnotetext{
${ }^{45}$ Nagel (1971)

${ }^{46}$ Nagel (1971), p. 718.

${ }^{47}$ Nagel (1971), pp. 719-720
} 
Leading a human life is a full-time occupation, to which everyone devotes decades of intense concern."

And he supports the claim about philosophical doubt by noting how it is always open to us to reconsider our life projects, to question their worth and value, and, more significantly, to question the entire scheme of justification in which we locate them. As he puts it, we always have the possibility to step back and view our lives sub specie aeternitatis: ${ }^{48}$

"We step back to find that the whole system of justification and criticism, which controls our choices and supports our claims to rationality, rests on responses and habits that we never question, that we should not know how to defend without circularity, and to which we shall continue to adhere even after they are called into question."

In this sense, his claim has certain similarities with the claims made by radical sceptics, who question whether we can really know anything (and Nagel duly acknowledges those similarities). He is simply appealing to a radical doubt about the seriousness of our pursuits.

How does this relate to the enhancement debate? Nagel's argument works irrespective of the availability of enhancement technologies, but there is a sense in which the availability of such technologies can heighten one's appreciation for the discrepancy at the heart of Nagel's argument. It may always be possible to engage in radical philosophical questioning of your projects, plans, aspirations and goals, but many people can happily avoid doing so, by returning once more in the "serious" details of their everyday lives. It takes a particular kind of philosophical sensibility to entertain the radical doubts on an ongoing basis. But if people were regularly confronted with enhancement technologies that allowed them to alter their moods and dispositions with ease, they might find the radical doubt to which Nagel appeals unavoidable. Indeed, one plausible interpretation of the Pharmacy of the Future thought experiment is that it is a heightened appreciation for the contingency of one's life project, and the scheme of justification in which it resides (one's desires), that causes the "vertiginous" feeling imagined by Owens.

${ }^{48}$ Nagel (1971), pp. 720. 
This suggests that one could flesh out the key premise of the hyperagency argument in the following manner:

$(2 * * * *)$ If we attain a state of hyperagency, we will have a heightened appreciation for the absurd (because the contingency and questionability of our life projects will become more apparent).

(Note that with this argument we return to the "attainment" version of the antecedent clause.) Is the argument persuasive? Two issues seem pressing here.

First, one must question Nagel's claim about the discrepancy between our aspirations and reality. The argument relies on the belief that all plans and projects are open to scepticism and doubt. But I find that hard to credit. There may be activities and states of affairs that are intrinsically and necessarily good and if there are these kinds of activities and states of affairs they would not be open to the doubts that Nagel's argument requires. If so, the discrepancy between aspiration and reality may not arise. Now, I am sure Nagel would reply by telling me that even putative intrinsic goods are open to questioning, just as his argument is open to questioning, and just as everything in philosophy is open to questioning. But is that really true? Is it really possible to doubt that torturing an innocent child for fun is just necessarily and intrinsically bad, and hence that a life dedicated to eradicating such a practice is intrinsically worthwhile? I certainly find it hard to doubt such things; I suspect others agree.

Second, it is an open empirical question as to whether we really would have this heightened sense of absurdity. David Owens may feel it; but others may not. The considerations adduced in response to Saskia Nagel's argument, above, could be important here. As I noted, people could avoid choice overload by adopting simple decision heuristics that filter out options quickly. Maybe this psychological trick would also block any appreciation of absurdity: people could be so wedded to a particular project or plan that they never seriously consider technologies that could alter their projects and plans.

In conclusion, although the application of Thomas Nagel's argument for absurdity to the enhancement debate is an intriguing possibility, I suspect it provides weak, 
somewhat uncertain support for the hyperagency objection. Nagel's argument works irrespective of the existence of radical enhancement technologies. It is not clear that the presence of such technologies would really make things any worse.

\section{Could Hyperagency Promote Meaning?}

The argument to this point has been critical: I have challenged four hyperagency objections, each of which claims that the pursuit or attainment of hyperagency could undermine subjective conditions for meaning and worthwhileness. I now want to move beyond the critical and build a positive case for enhancement and meaning in life. I do by considering two recent theories of meaning: Smuts's "Good Cause" account ${ }^{49}$ and Metz's “Transcending the Animal Self” account. I will argue that there are ways in which enhancement in general (and hyperagency in particular) can be channeled so as to satisfy the conditions that both author's associate with a meaningful and worthwhile life. I'll be brief here, presenting the arguments in a programmatic form, but still leaving time to address some final objections and rebuttals.

\section{1 - Enhancement and the Pursuit of Good Causes}

As hinted at above, purely subjectivist accounts of meaning are open to ridicule. If all that is needed for meaning is the satisfaction of desires, or the experience of subjective well-being, then any activity or desire, no matter how absurd or evil, could confer meaning. If I have a strong and overwhelming desire to count all the blades of grass in the world, then a lifetime spent doing this will be deemed meaningful (maybe even worthwhile) on a purely subjectivist account. But surely that is rest too much weight on the subjective? To generalise, the problem is that on a purely subjectivist or hybridist account, I can never be wrong about the conditions I need to satisfy to achieve meaning.

This problem leads some to defend an objectivist account of meaning. A recent example of this can be found in the work of Aaron Smuts. Although not inured to the role of subjective experience in theories of well-being, and not closed to the role of

\footnotetext{
${ }^{49}$ Smuts, forthcoming
} 
subjective conditions in an account of the ideal life,${ }^{50}$ he argues that meaning and worthwhileness are largely functions of objective good. To be precise, he holds that the meaning of your life is a function of the amount of objective good for which you are causally responsible. The more good you produce the better. In this manner, the objective goods provide the normative fixed points for action (contra Owens).

This account of meaning leaves plenty of room for debate about the constituents of the objective good. For illustrative purposes, we can imagine that the kinds of goods that feature on objective list versions of utilitarianism could constitute the objective good. Thus, a life spent curing cancer, producing great works of art, alleviating poverty, overcoming social injustice, and obtaining scientific knowledge would be highly meaningful one. I am sure none of these examples would provoke much dissent.

In any event, I am not concerned here with defending a particular account of the objective good, my aim is simply to argue that, if things like this are part of the objective good, and if meaning is (at least in part) a function of the objective good, enhancement technologies could help us all to live more meaningful lives. It seems obvious that this could be so, even when enhancement technologies have the kinds of extreme hyperagentic qualities that are lamented by others. The reason for this is that being causally responsible for the good is an arduous, sometimes psychologically difficult process. There are many psychological barriers to doing the right thing, producing great art, obtaining scientific knowledge. We are prone to akrasia (weakness of the will), conflicting desires and sometimes even downright evil desires. If enhancement technologies allow us to increase cognitive capacity, and directly manipulate of moods and emotions, those barriers could be overcome. Thus our path to a meaningful life becomes less bumpy. Just to be clear, this argument applies not only to the pure objective cause account of meaning proffered by Smuts, but also to any other theory of meaning that holds that the causal consequences of one's actions contribute to meaning.

One countervailing concern might be that enhancement technologies could be used to trivialise certain objective evils, or offer trivial methods for producing objective good. For example, if we agree that pain is intrinsically (objectively) bad, then we might assume that minimising pain (ceteris paribus) is a meaningful way to spend one's life.

\footnotetext{
${ }^{50}$ Smuts, forthcoming - comments on Wolf's Fitting Fulfillment theory.
} 
But if enhancement technologies could be used to make people instantly forget painful experiences, perhaps the objective badness of pain is trivialised? Or suppose that alleviating poverty and its attendant psychological distress is a meaningful goal in life. But suppose enhancement technologies allow us to generate experiences in the minds of the poor that trick them into thinking they are not poor and thereby minimise their distress. That might seem to solve the problem, but again there is something suspicious about it. Indeed, it may be that Owens's concern about the lack of normative constraints is best understood in these terms: if every experience, desire, mood, characteristic, belief and disposition becomes readily manipulable, then it is trivially easy to bring about the "objective good".

My response to this is an obvious one. The counterargument is relying on an impoverished, essentially hedonic view of the good. The assumption here is that producing the right kind of subjective experience in others is all that matters. I grant that hypothetical (but plausible) enhancement technologies could be used to produce those kinds of subjective experience, but I reject the notion that the argument here rests on such an impoverished account of the objective good. ${ }^{51}$ As Nozick's famous experience machine argument suggests, there is more to the good than subjective pleasure. If this is right, there is no reason to think enhancement itself trivialises the good. Thus, there is continuing reason to think it could assist us in bringing about other objective goods.

\section{2 - Enhancement and Transcending the Animal Self}

The positive case for enhancement is not limited to this one example. Thaddeus Metz has long defended a theory of meaning in life that fuses subjective and objective conditions (hence he can be seen as a proponent of hybridism). ${ }^{52}$ His focus is on the conditions of "great meaning" (in my vocabulary "worthwhileness"). He notes that there is a general consensus that certain objective ends confer great meaning on a life: a person who does great moral work, produces great art, or makes significant scientific discoveries lives a life of great meaning. But why?

\footnotetext{
${ }^{51}$ It's clear that Smuts's rejects this account too.

${ }^{52}$ See Metz (2003) for an early presentation. The version I discuss in the text comes from Metz (2011). It also features in Metz (2013).
} 
Metz argues that it is not just that these things are objectively worthy — though they are - it is that they demand and encourage certain subjective attitudes. First, they demand that we transcend our animal selves. That is to say: they require more than simply responding and reacting to our own biological needs (food, shelter, sexual release and so on). And second, they require an intellect that is positively oriented toward the fundamental objects (the good, the true and the beautiful).

Metz elaborates on this account at some length, explaining exactly what a fundamental object is ${ }^{53}$ and how doing great moral work, creating great art and making significant scientific discoveries exemplify the subjective attitudes to which he appeals. I'll eschew those details once more in order to defend my primary argument: that enhancement technologies can help us to satisfy those conditions of great meaning. The argument follows what was said previously. Contouring one's intellect to objects of fundamental importance, and transcending the animal self, is difficult. There are many psychological barriers to doing important moral, intellectual and aesthetic work. Direct powers of mood alteration and enhanced cognitive capacities could be obvious boons to this. Thus, if we attained hyperagency, we could get much closer to the lives of great meaning envisioned by Metz. ${ }^{54}$

There are a few problems with this though. One fly in the ointment relates to effort, and the role it may play in great meaning. One could argue — and indeed Metz gestures at this ${ }^{55}$ - that the sheer difficulty of contouring one's rational faculties to fundamental objects is part of what confers great meaning. If it weren't so difficult, it wouldn't be so meaningful. Thus, to the extent that enhancement makes it easier, it might sap away some of the meaning.

This is an interesting objection, and one worthy of consideration. I will only hint at a response here, since it has already been considered by others more fully. ${ }^{56}$ But to put the response simply, it cannot be that effort always and everywhere increases meaning. If that were true, one could make one's life more meaningful by arbitrarily making it more difficult to do good deeds, produce great art or make great discoveries. For example, Bill Gates could make his life more meaningful by arbitrarily losing all

\footnotetext{
${ }^{53} \mathrm{He}$ defines it (2011) as a condition of existence that is responsible for many other conditions.

${ }^{54}$ For what it is worth, Metz (2009) says some positive things about transhumanism.

${ }^{55}$ Metz (2011), particularly the comments on morality and intellectual sophistication.

${ }^{56}$ Douglas (2013).
} 
his money, then earning it back and then donating it to charity; rather than just by donating what he has already earned to charity. After all, the former is more effortful than the latter. This is clearly absurd: even if effort is part of the picture, the meaning must primarily come from the attitudes and their objects, not from their causal history. In any event, I suspect effort will still be present in large quantities in an enhanced world, partly because deciding to make use of enhancement technologies is itself going to be an effortful process, but also because it may open up newer, more effortful challenges for us to pursue. ${ }^{57}$

A second problem ${ }^{58}$ comes from Metz's endorsement of narrative structure as a key part of what makes life meaningful. ${ }^{59}$ This is something that is endorsed by others as well. ${ }^{60}$ According to this view, lives are meaningful not solely in virtue of the parts that make up a life (e.g. the great moral or artistic works) and but also in virtue of the connection between those parts. In particular, the narrative connection between those parts. One problem with hyperagentic enhancement is that in removing the psychological and physical barriers to meaningful work, it may also too readily allow us to erase or weaken the narrative connections between the various parts of our lives. For example, by changing our traits, dispositions and desires, or by selectively deleting our memories.

A degree of narrative structure/unity may well be needed in order to make life meaningful. Nevertheless, I think there are several responses one can make on behalf of hyperagentic enhancement. First, there is no reason to think that the enhancement project must be blind to the value of narrative structure. Indeed, when discussing Saskia Nagel's regret argument earlier in this article, I accepted this possibility by pointing out that regret may not be all that bad because it could play an important role in the narrative structure of an individual life. Second, there is no reason to think that the manner in which enhancement is used must disrupt narrative unity. For instance, even in the case of memory dampening, this may largely by effected through the dampening of emotional memories, not declarative memories. In other words, a person may still be

\footnotetext{
${ }^{57}$ I would like to thank an anonymous reviewer on an earlier draft of this article for encouraging me to make this latter point.

${ }^{58} \mathrm{I}$ am indebted to an anonymous reviewer for drawing this objection to my attention.

${ }^{59}$ Metz (2013), chapter 2, looks at the argument between what he calls "pure whole lifers" (i.e. those who think meaning is a property of the whole life) and "pure part lifers" (i.e. those who think meaning is a property of the parts of a life). In the end, Metz endorses a mixed view, which says that "what matters in life are both its parts and their overall relationship to one another" (p. 51).

${ }^{60}$ Metz (2013), pp. 38-49 reviews some of the literature.
} 
able to remember and recall traumatic events - and thereby be capable of weaving them into the story of their lives - but nevertheless be freed from the paralyzing emotions associated with those events. ${ }^{61}$ Third, it is not clear how constraining the narrative condition really is. After all, unity or connectivity between the parts of a life does not imply fixity. For example, if the narrative constraint is understood in essentially aesthetic terms, then there are many plausible and aesthetically appealing narrative structures - the picaresque springs to mind - which require minimal degrees of connectivity between the parts of the narrative. Finally, and most importantly, it seems that if narrative structure is to feature in an account of the meaningful life, it will need to be traded off against other aspects of what makes life meaningful. ${ }^{62}$ Thus, to require unity or connectivity at all costs would seem unwarranted, and could well deplete a life of meaning. For example, if a person's life has, up to a certain point, consisted of crippling trauma and repeated failures, then would it really be so bad to give them the opportunity to wipe the slate clean? I would suggest not and that, once again, extreme hyperagentic enhancement may actually help such a person live a more meaningful life.

\section{Conclusion}

To sum up, some people find something unsettling about the notion of hyperagency, not just for social or impersonal reasons, but for deeply personal reasons. That much is clear from the views addressed in this article. Certain authors find disquieting the claim that we could gain total mastery over ourselves, over our moods, dispositions, beliefs and desires. A plausible interpretation of this disquiet is that these authors believe that total mastery undermines conditions for meaningful and worthwhile life. But as I have argued it is difficult to mould this disquiet into a persuasive argument against enhancement. The four objections to the pursuit and attainment of hyperagency considered above in section 3, provide, at best, weak and defeasible grounds for rejecting enhancement. In many cases, the enhancement project could be channeled or directed in ways that avoid the concerns raised by those authors, and in many cases the authors are guilty of implausible overstatement. But that is not all. In addition to there being no strong case against enhancement on the grounds of meaning and worthwhileness, there are reasons to think that it could, even in an extreme hyperagentic

\footnotetext{
${ }^{61}$ See, however, Erler, (2011) for a more detailed discussion of the role of memory and memory dampening in the "authentic life".

${ }^{62}$ Metz (2013) p. 51-52 endorses this view.
} 
form, help rather than hinder us in satisfying the conditions for a meaningful and worthwhile life.

Acknowledgments: The author would like to thank Brian Earp, and two anonymous reviewers for comments on earlier versions of this paper.

\section{Bibliography}

Beike, DR, Markman, KD and Karadogan, F. 2009. What we regret most are lost opportunities: a theory of regret intensity. Personal and Social Psychological Bulletin 35(3): $385-397$

Bostrom, Nick. 2008. Why I want to be a posthuman when I grow up.

In Bert Gordijn and Ruth Chadwick (eds.) Medical Enhancement and Posthumanity. Berlin: Springer 107-136.

Bruckner, Donald. Unpublished. The Subjective Conception of Meaning in Life. Available for download at:

http://www.personal.psu.edu/dwb12/blogs/donald_bruckners_webpage/workingpapers.html, accessed 23/09/2013

Buchanan, Allen. 2011. Beyond Humanity? The Ethics of Biomedical Science. Oxford: OUP.

Douglas, Thomas. 2013. Enhancing Moral Conformity and Enhancing Moral Worth. Neuroethics, forthcoming. DOI 10.1007/s12152-013-9183-y

Erler, Alexander. 2011. Does Memory Modification Threaten our Authenticity? Neuroethics 4(3): 235-249.

Hauskeller, Michael. 2011. Human Enhancement and the Giftedness of Life. Philosophical Papers 40(1): 55 - 79.

Hauskeller, Michael. 2013. Better Humans? Understanding the Enhancement Project. London: Acumen.

Kamm, Frances. 2009. What is and what is not wrong with enhancement?. In Savulescu, J. and Bostrom, N. (Eds) Human Enhancement. Oxford: OUP.

Lewis, C.S. 2001. The Abolition of Man. New York, NY: HarperCollins. (Originally published 1944)

Metz, Thaddeus. 2002. Recent work on the meaning of life. Ethics 112: 781-814

Metz, Thaddeus. 2003. Utilitarianism and the Meaning of Life. Utilitas 15: 50-70 
Metz, Thaddeus. 2009. Imperfection as sufficient for a meaningful life: How much is enough?. In Nagasawa, Y. and Wielenberg, E. (Eds) New Waves in the Philosophy of Religion. London: Palgrave MacMillan.

Metz, Thaddeus. 2011. The Good, the True, and the Beautiful: Toward a Unified Account of Great Meaning in Life. Religious Studies 47: 389-409.

Metz, Thaddeus. 2013. Meaning in Life: An Analytic Study. Oxford: OUP.

Nagel, Saskia. 2010. Too Much of a Good Thing? Enhancement and the Burden of SelfDetermination. Neuroethics 3: 109-119

Nagel, Thomas. 1971. The Absurd. The Journal of Philosophy 68: 716-727

Owens, David. 2007. Disenchantment. In Louise Antony (ed) Philosophers without Gods. Oxford: OUP.

Pacholczyk, Anna and Harris, John. 2013. Dignity and Enhancement. In Nathan J Palpant and Stephen C Dilley (eds) Human Dignity in Bioethics. London: Routledge .

Roese, N. J. and Somerville, A. 2005. What we regret... and why?. Personal and Social Psychological Bulletin 31(9): 1273-1285

Scheibehenne, B., Greifeneder, R. and Todd, P.M. 2010. Can there ever be too many options? A Meta-Analytic Review of Choice Overload. Journal of Consumer Research 37: 409-425.

Schwartz, Barry. 2004. The Paradox of Choice: Why Less is More. New York, NY: Harper Collins.

Smuts, Aaron. Forthcoming. The Good Cause Account of the Meaning of Life.

Southern Journal of Philosophy. Author's version available at https://sites.google.com/site/asmuts/research/download-

papers/Smuts 12 TheGoodCauseAccount version4 20121211.pdf?attredirects $=0 \& \mathrm{~d}=1$ accessed 23/09/2013

Taylor, Richard. 2008. The Meaning of Life. In Klemke, E.D. and Steven M. Cahn (Eds.) The Meaning of Life. New York: Oxford University Press.

Vincent, Nicole. 2013. Enhancing Responsibility. In N A Vincent (ed) Neuroscience and Legal Responsibility. New York, NY: Oxford University Press.

Wielenberg, Erik. 2005. Value and Virtue in a Godless Universe. Cambridge: Cambridge University Press.

Wolf, Susan. 2010. Meaning in Life and Why it Matters. Princeton, NJ: Princeton University Press. 
